\title{
Reductions in Cardiac Output, Central Blood Volume, and Stroke Volume with Thermal Stress in Normal Men during Exercise *
}

\author{
Loring B. Rowell, $\nmid$ Herbert J. Marx, $\ddagger$ Robert A. Bruce, Robert D. Conn, $\S$ \\ AND Fusako KusUmi \\ (From the Department of Medicine, Division of Cardiology, University of Washington, \\ Seattle, Wash.)
}

Observations on heat-acclimatized men by Asmussen (1) and Williams and colleagues (2) showed no increase in cardiac output above the normal response during exercise in a hot, humid environment. Indeed, Asmussen found decrements in cardiac output below normal responses if moderate work in the heat $\left(32^{\circ} \mathrm{C}, 80 \%\right.$ relative humidity) was prolonged from 30 to 60 minutes. No systematic study has been reported of cardiac output during exercise at high ambient temperature in men unacclimatized to heat.

Metabolic requirements may be prepotent in the regulation of cardiac output, since Rowell and colleagues (3) observed no decrements in oxygen uptake of unacclimatized men during moderate to heavy exercise at $43.3^{\circ} \mathrm{C}\left(110^{\circ} \mathrm{F}\right)$ when compared with identical measurements on these men at $25.6^{\circ} \mathrm{C}\left(78^{\circ} \mathrm{F}\right)$. The failure to observe a significant increment in blood lactate concentration at $43.3^{\circ} \mathrm{C}$ suggested that there was minimal diversion of blood away from working skeletal

* Submitted for publication December 16, 1965 ; accepted August 11, 1966.

Supported by grant-in-aid HE-00908-C14 from the National Heart Institute and by the Washington State Heart Association. A portion of this work was conducted through the Clinical Research Center Facility of the University of Washington supported by the National Institutes of Health (grant FR-37).

Presented in part at the Thirty-eighth Scientific Sessions of the American Heart Association, Miami Beach, Fla., October 15, 1965.

† Address requests for reprints to Dr. Loring B. Rowell, Dept. of Medicine, University of Washington School of Medicine, Seattle, Wash. 98105.

$\ddagger$ Postdoctoral fellow of the U. S. Public Health Service (grant-in-aid T1-HE-5281). Present address: Dept. of Medicine, University of California Medical Center, San Francisco, Calif.

$\S$ Teaching and research scholar of the American College of Physicians. muscle to skin. Nevertheless, a significantly greater $(20 \%)$ quantity of blood was diverted away from the hepatic-splanchnic system during exercise at $43.3^{\circ} \mathrm{C}$ than at $25.6^{\circ} \mathrm{C}$. It was hypothesized that increments in cutaneous blood flow supplied by redistribution of blood flow away from splanchnic tissues [and the kidneys (4)] during work in the heat might eliminate the necessity for greater increments in cardiac output during work in these conditions. To test this hypothesis, we designed a study to measure cardiac output seven times during each of four intensities of exercise at both $25.6^{\circ} \mathrm{C}$ and $43.3^{\circ}$ $C$ in the same subjects (56 determinations per man). The type of subjects, the intensity and duration of exercise, and the environmental conditions simulated as closely as possible these features of our previous study (3). Each successive work load increased oxygen intake $4 \mathrm{ml}$ per $\mathrm{kg}$ of body weight per minute (about $300 \mathrm{ml}$ of oxygen per minute); the increment in cardiac output was estimated to be about $1.5 \mathrm{~L}$ per minute (5). This design would assess whether differences in cardiac output of this magnitude were significant when the variance of multiple determinations was analyzed. To decrease the large variability of multiple determinations of cardiac output with sampling of diluted indicator from peripheral arteries (6), we selected a central sampling site in the aortic arch. In addition, aortic sampling allowed more accurate measurements of central blood volume (CBV) by eliminating artifactual changes attending peripheral measurement of this volume $(7,8)$.

\section{Methods}

The subjects were normal, physically untrained men, ranging in age from 21 to 27 years, and unacclimatized to 
heat (Table I). Selection of ten subjects depended upon normal findings in a thorough physical examination and demonstration of willingness and ability to withstand severe work at $43.3^{\circ} \mathrm{C}$. Four subjects were eliminated later because of defective blood sampling due to fibrin formation in the aortic catheter.

Experiments were carried out from December through April in a room where air temperature was maintained at $25.6 \pm 1^{\circ} \mathrm{C} \mathrm{db}\left(78^{\circ} \mathrm{F}\right.$ dry bulb $)$ and $16.8 \pm 2^{\circ} \mathrm{C} \mathrm{wb}$ $\left(63^{\circ} \mathrm{F}\right.$ wet bulb $)$ or at $43.3 \pm 1^{\circ} \mathrm{C} \mathrm{db}\left(110^{\circ} \mathrm{F}\right)$ and 28.3 $\pm 1^{\circ} \mathrm{C} \mathrm{wb}\left(83^{\circ} \mathrm{F}\right)$ with minimal air movement at $43.3^{\circ}$ C. After room temperature had been changed, 3 days was allowed for equilibration before the room was used. All subjects performed the four levels of exercise to be employed in the experiments at $43.3^{\circ} \mathrm{C}$ and some also at $25.6^{\circ} \mathrm{C}$ several weeks before cardiac output was determined. Maximal oxygen intake was determined by the procedure and criteria of Taylor, Buskirk, and Henschel (9). The catheterization procedure was described in detail to all subjects, and some observed the experimental procedure in their colleagues.

Subjects were instructed to consume larger than normal quantities of salt and water the day before an experiment. They reported to the laboratory for experiments 2 to 3 hours after a limited meal. They were dressed in shorts and tennis shoes. Preparation of the subject and catheterization were performed at the temperature under study and required about 2 hours. Two subjects ( $\mathrm{MW}$ and $\mathrm{CJ}$ ) were studied first at $43.3^{\circ} \mathrm{C}$. An $80-\mathrm{cm}$, no. 5 Lehman catheter was introduced percutaneously at the antecubital fossa and advanced under fluoroscopic guidance into the superior vena cava to a point just above the right atrium. A specially prepared $70-$ to $80-\mathrm{cm}$ Teflon catheter (18 gauge, thin wall) was introduced percutaneously into the brachial artery of the same arm by a modified Seldinger technique with an Amplatz-type, Teflon catheter-needle. Except for AJ, in whom the catheter rested in the ascending aorta, the tip of the catheter was positioned in the descending aorta below the origin of the left subclavian artery. The position of the catheter was recorded so that positioning could be duplicated at the second catheterization.

Four intensities of exercise were performed for $15 \mathrm{~min}$ utes on a motor-driven treadmill at grades of $7.5,10,12.5$,

TABLE I

Data on subjects

\begin{tabular}{|c|c|c|c|c|c|c|c|}
\hline \multirow[b]{2}{*}{ Subject } & \multirow[b]{2}{*}{ Age } & \multirow[b]{2}{*}{ Height } & \multicolumn{2}{|c|}{ Weight } & \multirow{2}{*}{$\underset{\left(43.3^{\circ} \mathrm{C}\right)}{\mathrm{BSA}}$} & \multicolumn{2}{|c|}{$\begin{array}{l}\text { Maximal oxygen } \\
\text { consumption }\end{array}$} \\
\hline & & & $25.6^{\circ} \mathrm{C}$ & $43.3^{\circ} \mathrm{C}$ & & $25.6^{\circ} \mathrm{C}$ & $43.3^{\circ} \mathrm{C}$ \\
\hline & years & $\mathrm{cm}$ & \multicolumn{2}{|c|}{$k g$} & $m^{2}$ & \multicolumn{2}{|c|}{$L / \min$} \\
\hline TB & 21 & 171 & 70.9 & 68.6 & 1.83 & 3.80 & 3.80 \\
\hline TA & 21 & 172 & 73.7 & 74.6 & 1.86 & 3.34 & 3.27 \\
\hline AJ & 27 & 190 & 82.2 & 82.1 & 2.10 & 3.56 & 3.50 \\
\hline TS & 22 & 184 & 72.1 & 70.8 & 1.94 & 3.74 & 3.44 \\
\hline $\mathrm{CJ}$ & 22 & 185 & 75.5 & 73.2 & 1.95 & 4.25 & 4.19 \\
\hline MW & 25 & 185 & 85.4 & 86.5 & 2.14 & 4.12 & 4.02 \\
\hline Mean & 23 & 181 & 76.6 & 76.0 & 1.97 & 3.80 & 3.70 \\
\hline
\end{tabular}

and $15 \%$ at a speed of 3.5 miles per hour $(5.6 \mathrm{~km}$ per hour), with 15 - to 20 -minute rest periods (seated) interspersed between them. The catheterized arm rested on an arm board, adjusted to prevent leaning on this support. Oxygen consumption was determined two to three times during the two highest levels of work to discover any changes with time in the cost of work resulting from either increased support from the arm board or from decreased mechanical efficiency. 1 Expired air was collected during the last 3 minutes of exercise with either a low resistance Collins triple $J$ valve or a single $J$ valve with smaller dead space when ventilation rate was low. A balanced $350-\mathrm{L}$ Collins spirometer with wide lumen, low resistance tubing and connections was used; additional gas collections were made into 120 -L neoprene bags via a low resistance manifold system. Expired gas samples were analyzed by the Scholander microtechnique, with duplicates checking within $0.03 \%$ for both oxygen and carbon dioxide.

For determination of cardiac output $5 \mathrm{mg}$ of indocyanine green (ICG) was rapidly injected (in less than $\frac{1}{2}$ second) from a specially constructed injection system in parallel with a reservoir syringe containing the mixed volume of dye for the entire study. The $1-\mathrm{ml}$ injection syringe was calibrated to within $\pm 0.5 \mathrm{mg}$ of water at $25.6^{\circ} \mathrm{C}$ and at $43.3^{\circ} \mathrm{C}$. The catheter was kept filled with dye, and successive injections were made by displacement. To achieve maximal frequency response of the Gilford 103 IR densitometer ${ }^{2}$ and to eliminate pulsatile variations in its output in response to flowing blood, we set the sampling speed at $45.9 \mathrm{ml}$ per minute (Harvard withdrawal-infusion pump). The $90 \%$ response time to a step increase in optical density of flowing blood was 1.6 seconds. Not more than $40 \mathrm{ml}$ was withdrawn for any curve. Injections, which were made after the response of the densitometer to flowing blood had been stabilized, were as close to $2,4,6,8,10,12$, and 14 minutes during exercise as technically possible. After each curve had been recorded, blood was reinfused into the subject. Between curves a slow infusion of heparinized saline was maintained. Initially normal saline was used; afterwards, half-normal saline was used to avoid a salt gain that might suppress sweating at $43.3^{\circ} \mathrm{C}$. Since dilution curves cleared to within a few per cent of peak deflection before recirculation of indicator (Figure 1), cardiac output was calculated by direct computation of the area of the inscribed curve by rectangulation at $\frac{1}{2}$-second intervals (identical results were obtained by planimetry). Blood for three- to four-point calibration curves was drawn during rest-before exercise and again immediately after the final level of exercise. Two to three minutes was required to obtain the $65-\mathrm{ml}$ samples. Calibrations for each level of exercise were made in TB $\left(43.3^{\circ} \mathrm{C}\right)$, TA $\left(25.6\right.$ and $\left.43.3^{\circ} \mathrm{C}\right)$, and $\mathrm{CJ}\left(25.6^{\circ} \mathrm{C}\right)$. These subjects were not restudied within 1 month nor the others within 3 weeks.

1 Three to four measurements of oxygen consumption were made during exercise at both temperatures during preliminary tests. No time trends were observed.

${ }^{2}$ Gilford Instrument Laboratories, Oberlin, Ohio. 


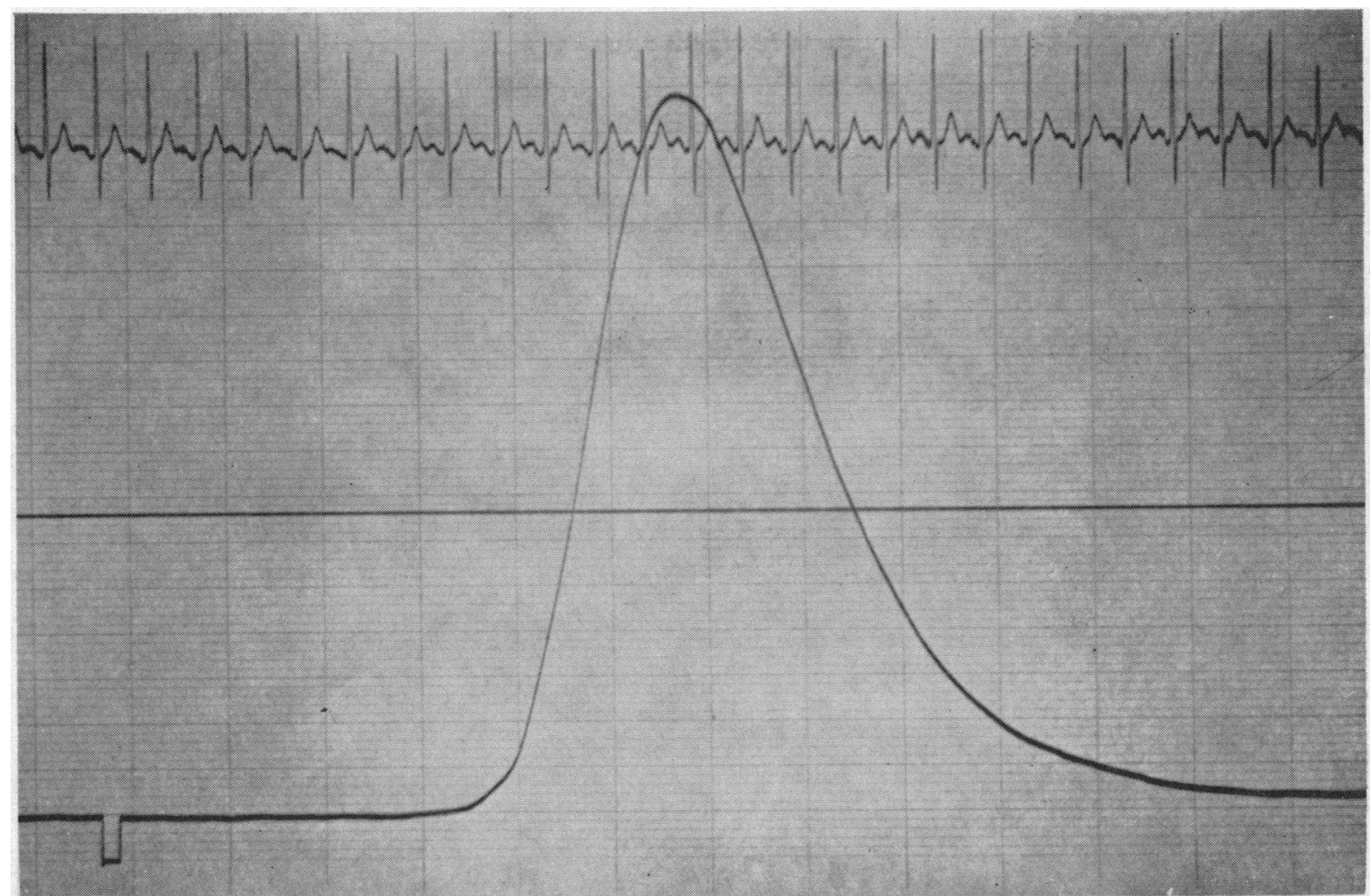

Fig. 1. AORTIC Indicator-Dilution curve. With central sampling there was minimal distortion due to delayed transit of indicator through vasoconstricted peripheral arteries and almost complete clearance before recirculation. Rapid sampling ( $45.9 \mathrm{ml}$ per minute) eliminated pulsatile variation in the curve.

The CBV was calculated from the product of cardiac output and corrected mean transit time (MTT), i.e., the MTT of the recorded curve less that of the sampling system. The MTT of each length of sampling system was determined by drawing (at $45.9 \mathrm{ml}$ per minute) undyed blood followed by a "square wave" of dyed blood through the system. The technique was similar to that of Fox, Sutterer, and Wood (10) except that the change in blood sampled was accomplished by rapidly turning a stopcock. The MTT of the sampling systems ranged from 1.6 to 2.0 seconds.

Throughout exercise rectal temperature was continuously monitored from a thermistor probe (accuracy, $-0.10^{\circ} \mathrm{C} ; 90 \%$ response time, 30 seconds) inserted 13 $\mathrm{cm}$ into the rectum. The ECG was successfully monitored throughout exercise at both temperatures by securing to antiperspirant-treated (a competitive inhibitor of acetylcholine) areas of skin either Telemedic ${ }^{3}$ or Beckman biopotential skin electrodes reinforced with gauze patches impregnated with collodion. All data were recorded via a Honeywell medical electronic system on a Honeywell visicorder (model 1508).4

Immediately after each period of exercise at $43.3^{\circ} \mathrm{C}$, the subject was stripped, wiped dry, and weighed to

3 Telemedics, Southampton, $\mathrm{Pa}$.

4 Honeywell, Denver Division, Denver, Colo. within $\pm 0.05 \mathrm{~kg}$. Ad libitum intake of water by mouth during recovery and infused saline during exercise were adjusted to maintain the subjects' body weights nearly constant throughout the experiment. Also, weighings before and after the experiments at $25.6^{\circ} \mathrm{C}$ indicated no significant change in weight.

Calibration. The densitometer, control unit, and recorder were calibrated precisely at $25.6^{\circ} \mathrm{C}$ and at $43.3^{\circ} \mathrm{C}$. Electronic modification of the Gilford 103 IR densitometer provided finer divisions in gain settings and increased sensitivity and linearity.

Despite stabilization of line voltage with a Sola transformer there were random jumps in output voltage from the densitometer. At the highest gain setting used during the study, these varied in frequency and magnitude from 0.1 to $1.0 \mathrm{cps}$ and $\pm 2 \%$ of the average peak amplitude of the dilution curves, respectively. Reproducibility of the response of the densitometer to a fixed concentration of ICG in blood was within \pm 2 to $3 \%$ of peak deflection. Since this variation was observed on a series of identical dilutions made from samples of the same blood, it also included variations in accuracy of our dilution technique (dilutions were made with a precision 25- $\mu 1$ syringe). Dilution accuracy was checked by measuring the ICG in separated plasma in a Beckman DU spectrophotometer $(805 \mathrm{~m} \mu)$. Variation in response, which was the same at $25.6^{\circ} \mathrm{C}$ and $43.3^{\circ} \mathrm{C}$, was there- 
fore mainly a function of low level random noise from the densitometer. At the lowest gain setting used during experiments, this random error was smallest (about $1 \%$ ).

The densitometer was found to have constant sensitivity to increments in ICG concentration up to background levels of $15 \mathrm{mg}$ per L. Background levels of dye were determined during several experiments but never exceeded $5 \mathrm{mg}$ per $\mathrm{L}$ despite progressive decrements in clearance rate with increasing severity of exercise, particularly at $43.3^{\circ} \mathrm{C}(3)$.

Since the response characteristics of the densitometer were the same at both ambient temperatures, calibrations during experiments were designed to correct for possible changes in the subject's blood or in the dye. Before the experiments the relationship between electrical-optical calibration (a wedge of known absorbency was inserted into the light path of the densitometer) and calibration on whole human blood was established. Since reproducibility and sensitivity of the densitometer could be checked optically (i.e., with the wedge), these characteristics were assessed when technically possible while blood was being sampled from the subject during or after exercise.

Possible significant changes in the spectral properties of ICG during the 3- to 4-hour experiment were assessed by removing samples of ICG from the mixed reservoir of dye before and immediately after experiments at $25.6^{\circ}$ $\mathrm{C}$ and $43.3^{\circ} \mathrm{C}$. Part of the dye was mixed with blood samples obtained before and after exercise. Decreases in densitometer output for a given concentration of ICG were due exclusively to changes in blood induced by exercise, particularly at $43.3^{\circ} \mathrm{C}$. Calibration studies were carried out in which arterial blood was sampled before and immediately after each level of exercise at $43.3^{\circ} \mathrm{C}$ and at $25.6^{\circ} \mathrm{C}$ in three men (in addition to the six subjects) to ascertain when these changes occurred. In addition, TS was restudied for the same purpose 4 weeks after his second experiment. In TS and two others a no. 5 Lehman catheter was placed in an axillary vein for dye injection, and a Cournand needle was placed in a radial artery. Every detail of the first experiment on TS at $43.3^{\circ} \mathrm{C}$, except for measurement of cardiac output, was repeated at this temperature. Blood for calibration (65 $\mathrm{ml}$ ) was sampled at rest and immediately after completion of each level of exercise. A third man was studied in the same manner as the regular experimental subjects except that the arterial catheter was in the right subclavian artery. In this subject dye curves were recorded during exercise, and blood was taken for calibration after each level of exercise.

Mensuration errors in calculation of cardiac output were minimized by using gain settings that allowed nearly full scale peak deflection $(13$ to $15 \mathrm{~cm}$ ) for dye curves at all levels of exercise. Calibrations were made on each subject's blood at each gain setting used (usually only two settings were required).

Statistical methods. All data were analyzed statistically by means of appropriate computer programs. Plots $(x-y)$ of cardiac output versus time, regression equations, correlation coefficients, means, standard devia- tions, coefficients of variation, and $t$ test values were computed for all data at both temperatures. Also, measurements were pooled for all individuals, and analysis of covariance was performed with respect to work load, ambient temperature, time of measurement, body weight, and different individuals.

\section{Results}

Data from six subjects are summarized in Table II.

Cardiac output. High ambient temperature significantly reduced cardiac output during moderate to severe exercise of short duration. An analysis of covariance was carried out with the model $\mathrm{Y}_{\mathrm{ijk}}=\mu+\mathrm{P}_{\mathrm{i}}+\mathrm{T}_{\mathrm{j}}+\mathrm{W}_{\mathrm{k}}+\beta_{1}\left(\mathrm{t}_{\mathrm{ijk}}\right)+\beta_{2}$ $\left(m_{1}\right)$, where $Y_{1 j k}$ is the observed value, $\mu$ is the grand mean, and $P_{i}, T_{j}, W_{k}, \beta_{1}\left(t_{i j k}\right)$, and $\beta_{2}$ $\left(m_{1}\right)$ represent the effects on $Y_{i j k}$ of testing different persons at different ambient temperatures, work loads, sampling times, and with different body weights, respectively. Each of these parameters had a highly significant effect on cardiac output at the level of $p<0.0005$. The effect of

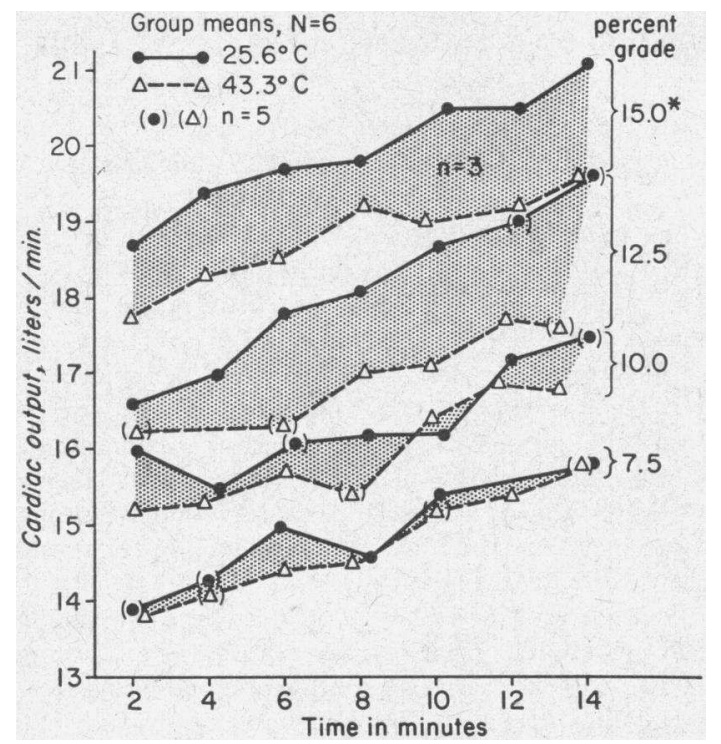

Fig. 2. Average Responses of Cardiac output to exERCISE AT $25.6^{\circ} \mathrm{C}$ AND $43.3^{\circ} \mathrm{C}$. Solid circles indicate means of all cardiac outputs measured at $25.6^{\circ} \mathrm{C}$ within \pm 1 minute of specified times and are plotted with respect to the average time of observation at each of four work loads (indicated as per cent grade). Open triangles represent corresponding data at $43.3^{\circ} \mathrm{C}$. Symbols enclosed in parentheses indicate that data from one subject are missing at that time. At the highest work load (15\% grade) only three subjects who completed the test at both temperatures were compared. 
testing different persons was, of course, random, whereas high ambient temperature reduced cardiac output; both work load (or oxygen consumption) and increasing time of measurement during work had the effect of increasing cardiac output.

The effect of temperature on cardiac output was very small during the first two levels of exercise ( 7.5 and $10 \%$ grades) (Figure 2 ); average values at the two grades were 15.0 and $16.4 \mathrm{~L}$ per minute at $25.6^{\circ} \mathrm{C}$ and 14.8 and $16.0 \mathrm{~L}$ per minute at $43.3^{\circ} \mathrm{C}$, respectively (Table II). When the intensity of exercise was further increased (12.5 and $15 \%$ grades), the decrease in cardiac output in the heat became more marked. At the third level of exercise (12.5\% grade) cardiac output was $1.1 \mathrm{~L}$ per minute lower at $43.3^{\circ}$ C. Measurements of cardiac output were obtained from only three subjects at both temperatures during the highest (15\% grade) level of exercise. Two men (TA and TB) were physically unable to achieve this level of exertion at $43.3^{\circ} \mathrm{C}$, and the data were questionable on a third subject (CJ) at $25.6^{\circ} \mathrm{C}$ because of difficulty with aortic blood sampling (Figure 3 ). At this level of work the cardiac output averaged $1.2 \mathrm{~L}$ per minute less at $43.3^{\circ} \mathrm{C}$ than at $25.6^{\circ} \mathrm{C}$ (Table II).

As expressed in Table II, the variance of cardiac output was mainly a function of the slope relating it to time rather than the scatter of observations about this regression line. Nevertheless, levels of significance were assigned to very small differences induced by work or ambient temperature or both. After separation of the effects of different individuals, ambient temperature, work load, time of measurement, and body weight, the standard deviation of the pooled observations was only $\pm 0.78 \mathrm{~L}$ per minute, and the coefficient of variation was $4.7 \%$.
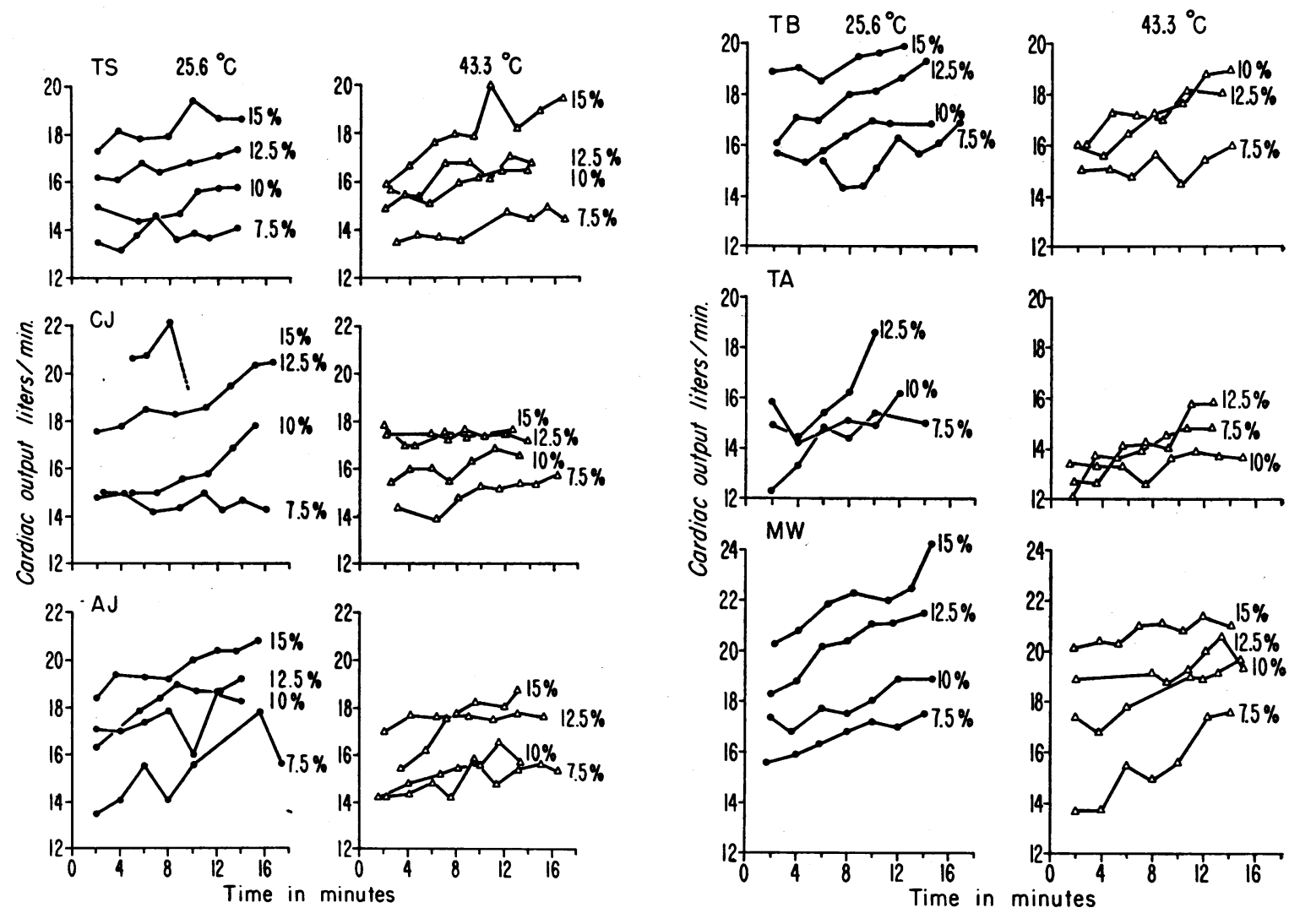

Fig. 3. Cardiac output during exercise. Solid circles on the left of each plate indicate values for cardiac output with respect to time and work load, indicated by the per cent grade at $25.6^{\circ} \mathrm{C}$ for each of six subjects. Open triangles on the right of each plate indicate data for each subject at $43.3^{\circ} \mathrm{C}$. 
TABLE II

Summairy of grouped data (uncorrected for time trends, body weight, etc.) for cardiac output, arteriovenous oxygen difference, oxygen intake, heart rate, and rectal temperature

\begin{tabular}{|c|c|c|c|c|c|c|c|c|}
\hline \multirow[b]{2}{*}{ Variable } & \multirow[b]{2}{*}{$\begin{array}{c}\text { Ambient } \\
\text { temperature }\end{array}$} & \multirow[b]{2}{*}{$\begin{array}{l}\text { Work } \\
\text { load, } \\
3.5 \mathrm{mph}\end{array}$} & \multirow[b]{2}{*}{$\begin{array}{l}\text { No. of } \\
\text { observa- } \\
\text { tions }\end{array}$} & \multirow[b]{2}{*}{ Means } & \multicolumn{2}{|c|}{ p valuet } & \multirow[b]{2}{*}{ SD } & \multirow[b]{2}{*}{$\mathrm{CV}^{*}$} \\
\hline & & & & & $\begin{array}{l}\text { Temper- } \\
\text { ature } \\
\text { effect }\end{array}$ & $\begin{array}{l}\text { Work } \\
\text { effect }\end{array}$ & & \\
\hline \multirow{8}{*}{$\begin{array}{l}\text { Cardiac } \\
\text { output, } \\
L / \text { min }\end{array}$} & \multirow[t]{4}{*}{$25.6^{\circ} \mathrm{C}$} & $\begin{array}{c}\text { \% grade } \\
7.5\end{array}$ & 44 & 15.0 & & & 1.24 & $\begin{array}{l}\% \\
8.3\end{array}$ \\
\hline & & 10.0 & 40 & 16.4 & & & 1.30 & 7.9 \\
\hline & & 12.5 & 41 & 18.1 & & \multirow{2}{*}{$\begin{array}{l}<0.001 \\
<0.001\end{array}$} & 1.70 & 9.4 \\
\hline & & $15.0 \ddagger$ & 28 & 19.8 & & & 1.60 & 8.1 \\
\hline & \multirow[t]{4}{*}{$43.3^{\circ} \mathrm{C}$} & 7.5 & 46 & 14.8 & NS* & \multirow{4}{*}{$\begin{array}{l}<0.001 \\
<0.001 \\
<0.001\end{array}$} & 0.98 & 6.6 \\
\hline & & 10.0 . & 43 & 16.0 & NS & & 1.76 & 11.0 \\
\hline & & 12.5 & 41 & 17.0 & $<0.001$ & & 1.76 & 10.4 \\
\hline & & $15.0 \ddagger$ & 30 & 18.6 & $<0.001$ & & 1.52 & 8.2 \\
\hline \multirow{8}{*}{$\begin{array}{l}\text { Oxygen, } \\
\text { intake, } \\
\mathrm{ml} / \mathrm{kg} / \mathrm{min}\end{array}$} & \multirow[t]{4}{*}{$25.6^{\circ} \mathrm{C}$} & 7.5 & 6 & 24.5 & & \multirow{4}{*}{$\begin{array}{l}<0.001 \\
<0.001 \\
<0.001\end{array}$} & 1.62 & 6.6 \\
\hline & & 10.0 & 6 & 28.6 & & & 0.99 & 3.5 \\
\hline & & 12.5 & 8 & 32.1 & & & 0.67 & 2.1 \\
\hline & & 15.0 & 10 & 36.4 & & & 2.21 & 6.1 \\
\hline & \multirow[t]{4}{*}{$43.3^{\circ} \mathrm{C}$} & 7.5 & 6 & 24.8 & NS & \multirow{4}{*}{$\begin{array}{l}<0.001 \\
<0.001 \\
<0.001\end{array}$} & 2.05 & 12.0 \\
\hline & & 10.0 & 6 & 28.0 & NS & & 1.82 & 6.5 \\
\hline & & 12.5 & 11 & 32.7 & NS & & 1.89 & 5.8 \\
\hline & & 15.0 & 11 & 36.0 & NS & & 2.14 & 5.9 \\
\hline \multirow{8}{*}{$\begin{array}{l}\text { Arteriovenous oxygen } \\
\text { difference, } \\
m l / 100 \mathrm{ml}\end{array}$} & \multirow{4}{*}{$25.6^{\circ} \mathrm{C}$} & 7.5 & 44 & 12.6 & & \multirow{4}{*}{$\begin{array}{c}<0.001 \\
\text { NS } \\
<0.001\end{array}$} & 0.83 & 6.6 \\
\hline & & 10.0 & 40 & 13.5 & & & 0.65 & 4.8 \\
\hline & & 12.5 & 41 & 13.8 & & & 1.04 & 7.6 \\
\hline & & 15.0 & 28 & 15.0 & & & 0.91 & 6.1 \\
\hline & \multirow[t]{4}{*}{$43.3^{\circ} \mathrm{C}$} & 7.5 & 46 & 12.7 & NS & \multirow{4}{*}{$\begin{array}{l}<0.010 \\
<0.001 \\
<0.001\end{array}$} & 1.01 & 8.0 \\
\hline & & 10.0 & 43 & 13.4 & NS & & 1.27 & 9.5 \\
\hline & & 12.5 & 41 & 14.5 & $<0.02$ & & 1.48 & 10.2 \\
\hline & & $15.0 \ddagger$ & 30 & 14.9 & NS & & 1.08 & 7.2 \\
\hline \multirow{5}{*}{$\begin{array}{l}\text { Heart rate, } \\
\text { beats } / \text { min }\end{array}$} & \multirow[t]{4}{*}{$25.6^{\circ} \mathrm{C}$} & 7.5 & & 136 & & \multirow{4}{*}{$\begin{array}{l}<0.001 \\
<0.001 \\
<0.001\end{array}$} & 15.6 & 11.5 \\
\hline & & 10.0 & & 151 & & & 13.1 & 8.7 \\
\hline & & 12.5 & & 163 & & & 11.3 & 6.9 \\
\hline & & $15.0 \ddagger$ & & 174 & & & 6.1 & 3.5 \\
\hline & $43.3^{\circ} \mathrm{C}$ & 7.5 & & 159 & $<0.001$ & $<0.001$ & 15.5 & 9.7 \\
\hline
\end{tabular}

${ }^{*} \mathrm{CV}=$ coefficient of variation (standard deviation/mean $\times 100$ ); NS $=$ not significant at $\mathrm{p}>.05$.

$\dagger \mathrm{p}$ values (paired $t$ test) indicate the significance of the differences in values resulting from increased work intensity and ambient temperature. Only measurements made within \pm 1 minute of each other were paired and tested; thus the number of observations paired with respect to temperature is smaller than that shown for means.

$\ddagger$ Averages from four men (TB completed this work load at $25.6^{\circ} \mathrm{C}$ only and CJ at $43.3^{\circ} \mathrm{C}$ ). 
TABLE II-(Continued)

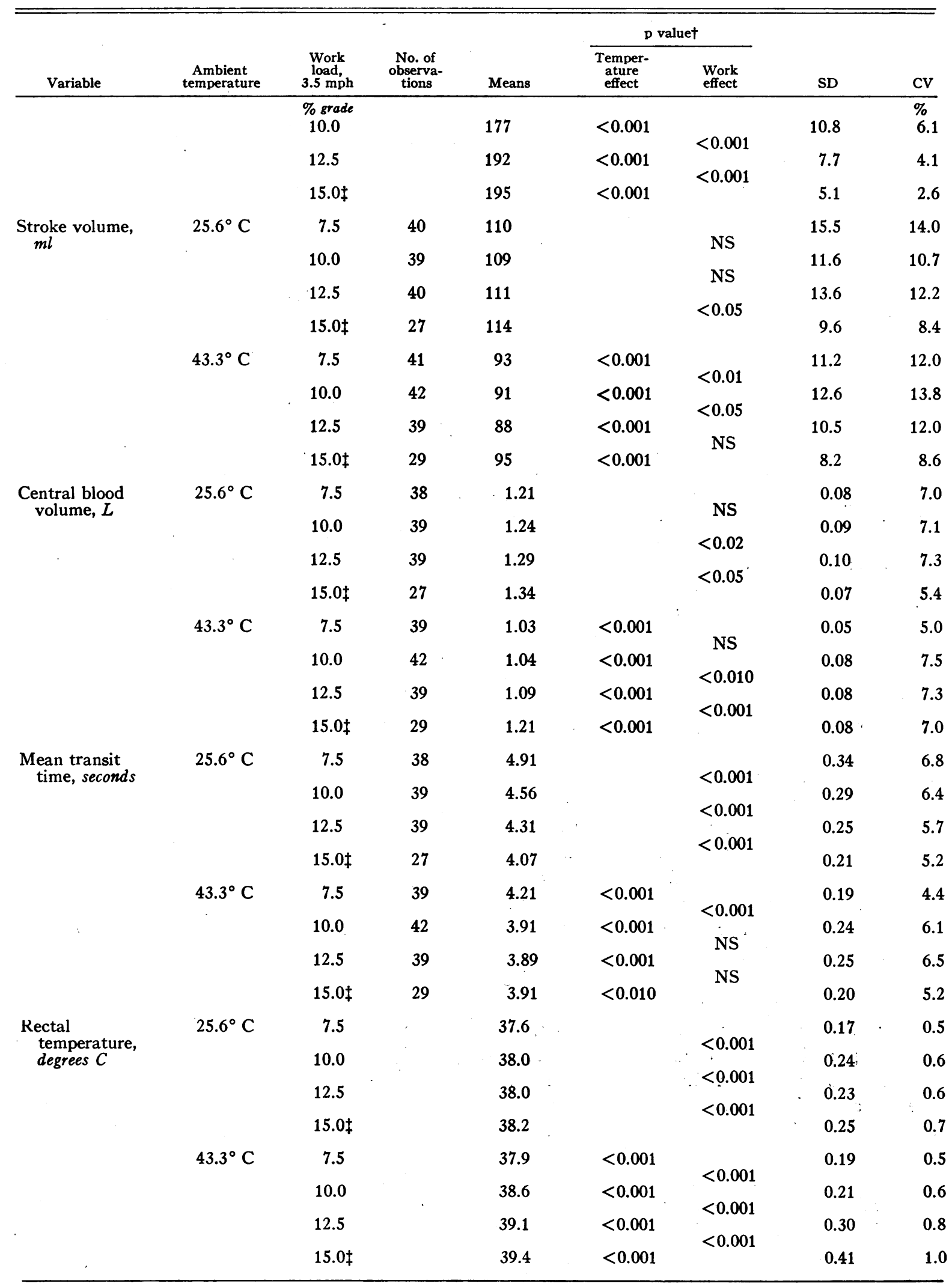




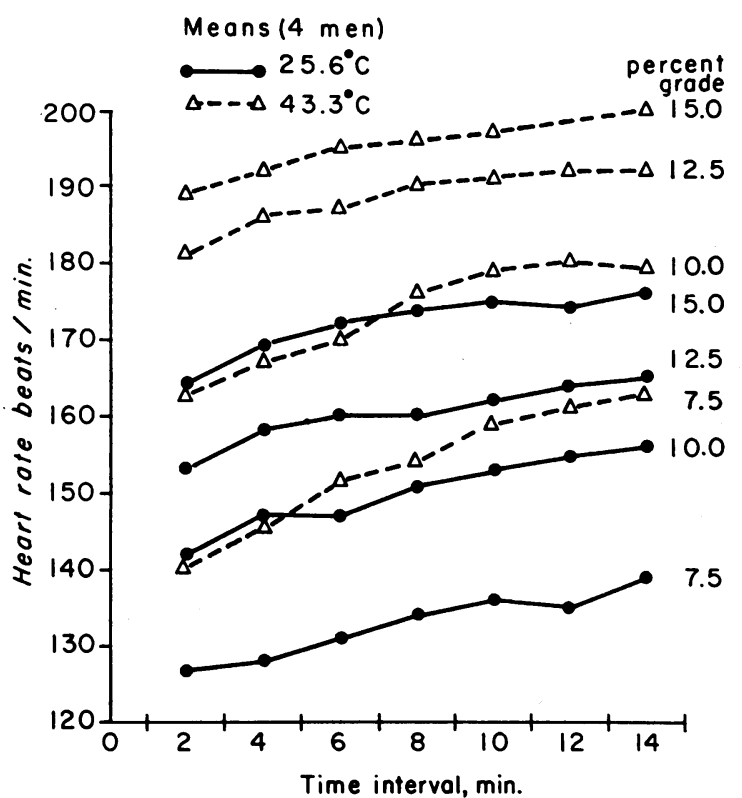

Fig. 4. Heart rate DURING exercise. Solid lines show the increase in heart rate with time and with each of four work loads, indicated by per cent grade at $25.6^{\circ} \mathrm{C}$. Dashed lines represent the responses at $43.3^{\circ} \mathrm{C}$. Each point represents an average of four men who performed four degrees of exercise at $25.6^{\circ} \mathrm{C}$ or at $43.3^{\circ} \mathrm{C}$; values were averaged over a time interval within \pm 1 minute of the specified time $(2,4,6$, etc. minutes $)$.

Individual subjects (Figure 3) showed little deviation from the average responses of the group shown in Figure 2. Subject TS was exceptional in that his cardiac outputs were the same at both temperatures at all work loads except the second (10\% grade), where he showed a 700 $\mathrm{ml}$ per minute increase at $43.3^{\circ} \mathrm{C}$. In addition, subject $\mathrm{TB}$ showed an $840 \mathrm{ml}$ per minute increase in cardiac output at this same work load. Early during the first work load MW showed a markedly lower cardiac output at $43.3^{\circ} \mathrm{C}$, but values rose to the same level obtained at the end of the work load at $25.6^{\circ} \mathrm{C}$. Those subjects whose heart rates approached maximal values during the second or third work load at $43.3^{\circ} \mathrm{C}$ ( TA, CJ, and AJ) showed an inability to increase cardiac output for the higher work load.

As stated above, there was significant time effect for cardiac output. For the group the average rates of increase in cardiac output with time at $25.6^{\circ}$ were $130,132,250$, and 176 (three men) $\mathrm{ml}$ per minute per minute during the first through fourth work loads, respectively. Over a 14-minute period of exercise these values represent increments of 1.8, 1.8, 3.5, and $2.5 \mathrm{~L}$ per minute. At $43.3^{\circ} \mathrm{C}$ comparable values were 2.1 , 2.2, 2.0, and 2.0 (three men) L per minute.

Oxygen consumption and heart rate. As reported previously (3), neither submaximal nor maximal oxygen consumption during the exercise was significantly affected by ambient temperature, under these experimental conditions (Table II). Only small decreases in maximal oxygen intake were seen with increased ambient temperature (Table I). The averages at $25.6^{\circ} \mathrm{C}$ and $43.3^{\circ} \mathrm{C}$ were 3.80 and $3.70 \mathrm{~L}$ per minute, respectively. When corrected for changes in body weight over the 5-month course of this study, values expressed as milliliters of oxygen per kilogram per minute were $49.8 \pm 5.1\left(25.6^{\circ} \mathrm{C}\right)$ and $49.1 \pm 5.7\left(43.3^{\circ}\right.$ C). There was no increment in oxygen consumption with time during the two highest levels of work at either temperature.

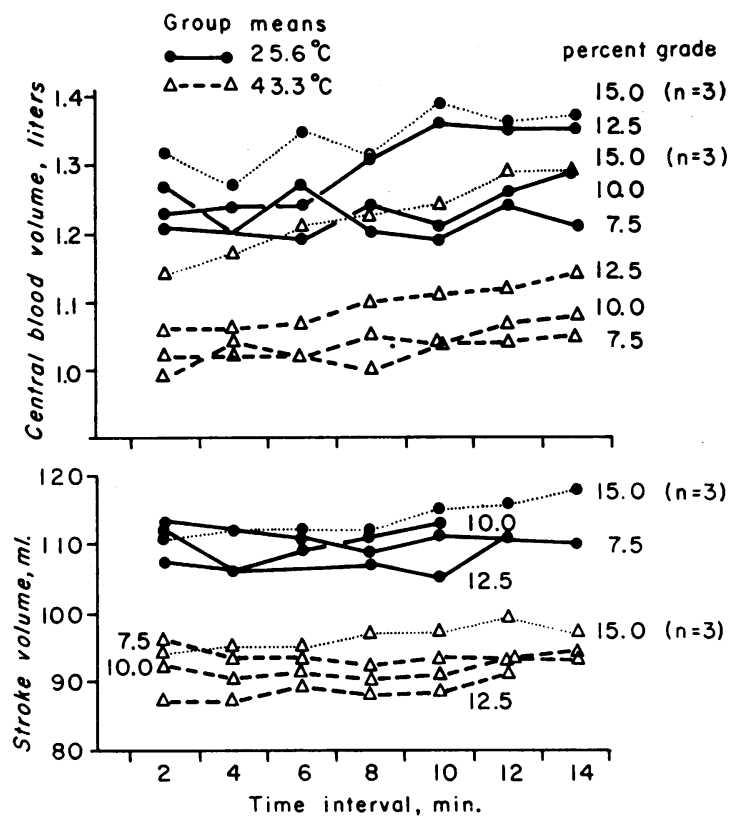

Fig. 5. Average responses of central blood volume AND STROKE VOLUME TO EXERCISE AT $25.6^{\circ} \mathrm{C}$ AND $43.3^{\circ} \mathrm{C}$. Solid circles indicate means of all central blood volumes (upper) and stroke volumes (lower) measured at $25.6^{\circ} \mathrm{C}$ within \pm 1 minute of specified times and are plotted with respect to the average time of observation at each of four work loads (indicated as per cent grade). Open triangles (dashed lines) represent corresponding data at $43.3^{\circ} \mathrm{C}$. Dotted lines indicate responses of three subjects who completed the highest work load (15\% grade) at both $25.6^{\circ} \mathrm{C}$ and $43.3^{\circ} \mathrm{C}$. 
TABLE III

Average decrements in $C B V, M T T$, and stroke volume at $43.3^{\circ} \mathrm{C}$ below control values at $25.6^{\circ} \mathrm{C}$

\begin{tabular}{cccc}
\hline & \multicolumn{3}{c}{ Percentage decrement } \\
\cline { 2 - 4 } $\begin{array}{c}\text { Work } \\
\text { load, } \\
3.5 \text { mph }\end{array}$ & CBV & MTT & $\begin{array}{c}\text { Stroke } \\
\text { volume }\end{array}$ \\
\hline $\begin{array}{c}\text { grade } \\
7.5\end{array}$ & 15 & 14 & 15 \\
10.0 & 16 & 14 & 16 \\
12.5 & 16 & 10 & 21 \\
15.0 & 8 & 3 & 17 \\
\hline
\end{tabular}

Heart rate was markedly elevated during work at $43.3^{\circ} \mathrm{C}$, reaching or exceeding 200 beats per minute in five men. Four subjects exhibited nearly maximal heart rates during the level of exercise that preceded their final work load in the heat. There was a distinct trend for heart

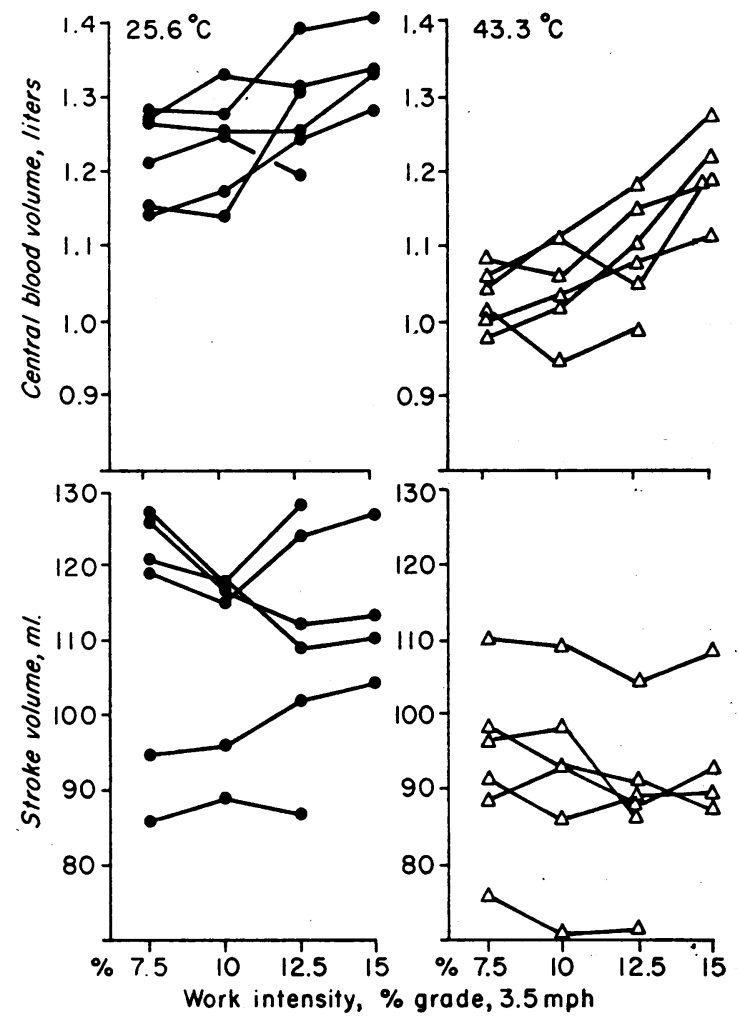

Fig. 6. RELATIONSHip OF CENTRAL blood VOLUME AND STROKE VOLUME TO INTENSITY OF EXERCISE AT $25.6^{\circ} \mathrm{C}$ AND $43.3^{\circ} \mathrm{C}$. On the left responses at $25.6^{\circ} \mathrm{C}$ are plotted for six men at each work load. Each solid circle represents the average of all measurements (usually seven) for a single subject at a given work load. Solid lines connect the data for a given subject at each work load. Corresponding responses at $43.3^{\circ} \mathrm{C}$ (open triangles) are on the right. rate to rise slowly with time throughout exercise, especially at $43.3^{\circ} \mathrm{C}$ (Figure 4).

Stroke volume. Stroke volume was also very significantly $(p<0.0005)$ reduced below control values during exercise at $43.3^{\circ} \mathrm{C}$ (Table II, Figure 5). During the two lower levels of exercise percentage reductions closely paralleled those in $\mathrm{CBV}$ and MTT (Table III). At the higher work loads reductions in stroke volume in the heat were greater. Unlike the lower work loads a considerable fall in cardiac output was contributory. This was most marked at the third work load, in which data were obtained from six subjects.

All parameters in the analysis of covariance significantly affected stroke volume at the level of $p<0.0005$, except work load, which was significant at $p<0.025$. The effects of time of measurement (Figure 5) and work intensity (Figure 6), however, were very small.

Subject TS, who maintained control values for cardiac output and had the least elevation in heart rate at $43.3^{\circ} \mathrm{C}$, showed the smallest decrements in stroke volume with exercise at this temperature (average $9 \%$, range 3 to $14 \%$, Figure 7).

Arteriovenous oxygen difference. The a-v oxygen difference was increased significantly $(\mathrm{p}<$ 0.0005 ) by high ambient temperature (Figure 8 ). Since this measurement was obtained by division of oxygen consumption by cardiac output, changes

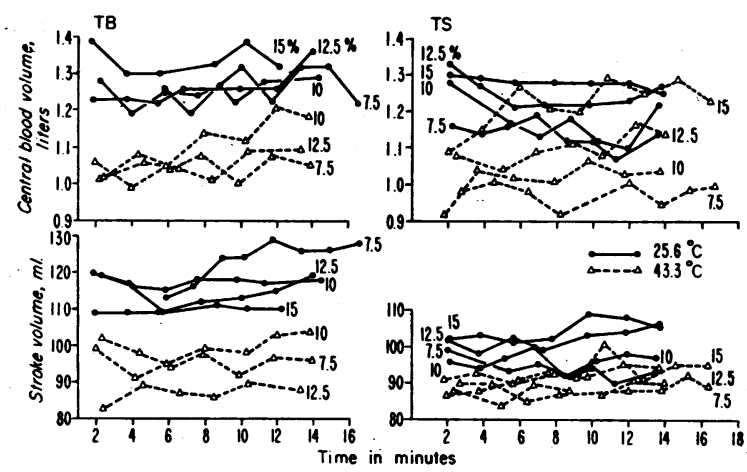

Fig. 7. Responses of CENTRAL BLOOD volume AND STROKE VOLUME WITH RESPECT TO TIME, TEMPERATURE, AND WORK LOAD IN TWO SUBJECTS. The symbols are the same as described for Figure 5. Values are plotted against the actual time of observation. The responses of TB are representative of those for five subjects. TS was exceptional in showing the least reduction in central blood volume and stroke volume at $43.3^{\circ} \mathrm{C}$ (TS was the only subject to show no decrement in cardiac output at $43.3^{\circ} \mathrm{C}$ ). 


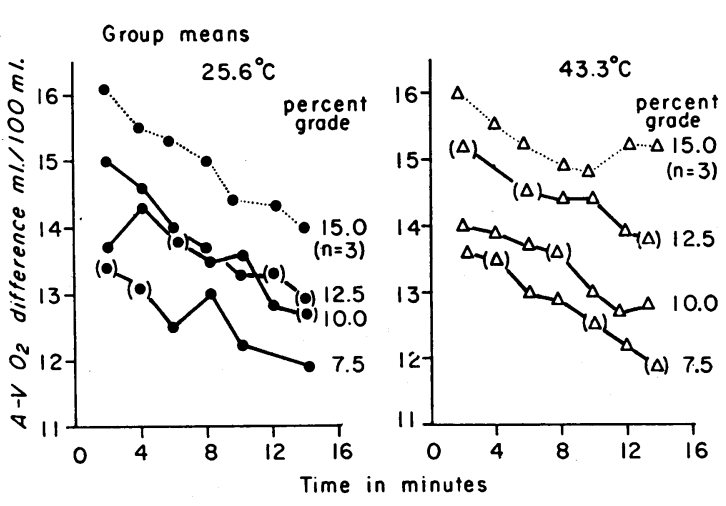

Fig. 8. Average arteriovenous (A-v) oxygen difFERENCE DURING EXERCISE. On the left averages of all $a-v$ oxygen differences at $25.6^{\circ} \mathrm{C}$ (solid circles) are plotted with respect to average time of measurement (within \pm 1 minute of specified time). Open triangles on the right indicate corresponding data at $43.3^{\circ} \mathrm{C}$. Symbols enclosed in parentheses indicate that data from one subject are missing at that time. Dotted lines indicate that only three men were compared at the highest work load (15\% grade).

in a-v oxygen difference simply are related reciprocally to changes in cardiac output when oxygen consumption is constant. Thus, at any given work load (or oxygen consumption) the effects of time of measurement, temperature, etc., were all highly significant.

Central blood volume. Each of the parameters in the statistical model had a highly significant effect on CBV $(p<0.0005)$. High ambient temperature $\left(43.3^{\circ} \mathrm{C}\right)$ had the greatest effect, causing a 15 to $16 \%$ decrease in $\mathrm{CBV}$ at the first three work loads (Table III, Figure 5). Although highly significant, the effects of work intensity and time of measurement during exercise were very small, particularly the latter (Table II). $\mathrm{CBV}$ increased only $80 \mathrm{ml}$ and $60 \mathrm{ml}$ during the first three work loads at $25.6^{\circ} \mathrm{C}$ and $43.3^{\circ}$ $\mathrm{C}$, respectively (Figure 6 ). The most marked increase in CBV occurred between the third and fourth work loads at both temperatures, $50 \mathrm{ml}$ at $25.6^{\circ} \mathrm{C}$ and $120 \mathrm{ml}$ at $43.3^{\circ} \mathrm{C}$ (four men). As a result of the greater increment in CBV during the fourth stage of work at $43.3^{\circ} \mathrm{C}$ (only three men were compared), the reduction in CBV below the response at $25.6^{\circ} \mathrm{C}$ was only $8 \%$. The smallest reduction in $\mathrm{CBV}$ with exercise at $43.3^{\circ}$ C occurred in TS (average $11 \%$, range 5 to $14 \%$, Figure 7), who was the only subject to increase cardiac output to normal levels during exercise at $43.3^{\circ} \mathrm{C}$.

Mean transit time. The MTT was very significantly reduced in response to high ambient temperature during exercise $(p<0.0005)$. Percentage reductions paralleled those in $\mathrm{CBV}$ ranging from 10 to $14 \%$ during the first three levels of exertion (Table III). At $25.6^{\circ} \mathrm{C}$ MTT decreased in a stepwise manner from 4.91 seconds at the first work load to 4.07 seconds at the fourth work load (Table II). In addition, MTT decreased with time during exercise while cardiac output increased. At $43.3^{\circ} \mathrm{C}$ MTT decreased with increased work intensity from 4.21 seconds to 3.89 seconds. This decrement occurred almost entirely between the first two work loads, and average values did not change thereafter.

Rectal temperature. Rectal temperature increased at essentially the same rate throughout the course of each work load at both temperatures. Increments ranged from 0.02 to $0.05^{\circ} \mathrm{C}$ per minute (average, $0.03 \pm 0.01^{\circ} \mathrm{C}$ per minute) at $25.6^{\circ} \mathrm{C}$; the average at $43.3^{\circ} \mathrm{C}$ was also 0.03 $\pm 0.01^{\circ} \mathrm{C}$ per minute (range 0.02 to $0.05^{\circ} \mathrm{C}$ per minute). Rectal temperature rose slowly during the recovery periods after exercise at $43.3^{\circ} \mathrm{C}$, whereas it slowly fell during recovery at $25.6^{\circ} \mathrm{C}$. Temperature responses were very similar to those illustrated graphically for the same conditions in a previous study (3) (Table II).

Calibration changes. Calibration changes, manifested as a decrease in absorbency of blood (at $800 \mathrm{~m} \mu$ ) containing a known concentration of dye, occurred during exercise in all but one subject (MW showed only a small change at either temperature). The greatest changes occurred at $43.3^{\circ} \mathrm{C}$. Had the calibration samples taken before exercise been used for calculation of cardiac output, values would have been raised as much as $4 \mathrm{~L}$ per minute. In those subjects from whom blood was drawn at rest shortly after each level of exercise the only significant change in absorbency occurred between withdrawal of the first arterial sample early in the catheterization procedure and the end of the first level of exercise. Therefore, only blood taken after exercise provided the correct reference calibrations for determining cardiac output. Changes in serum 
sodium concentration, hematocrit, or mean red cell volume were not of sufficient magnitude to provide clues as to the cause of the changes. Undoubtedly occasional small increases in hematocrit observed ( 1 to $3 \%$ from rest before exercise to the end of each level of exercise) accounted for part of the decreased sensitivity.

\section{Discussion}

Experimental design. Since the objective of our study was to investigate the initial strain imposed by combined thermal and exercise stresses rather than the result of adaptation to them, only men who were unacclimatized to heat and physically unconditioned were studied. The risk of acquiring partially acclimatized men was minimized also by the latter criterion (11).

To minimize any systematic effect of apprehension upon the initial study, we planned to study an equal number of men, randomly selected, at the higher temperature first. Results from those two men successfully studied at $43.3^{\circ} \mathrm{C}$ first indicated no apparent difference on this basis. In addition, to simplify interpretation of the results, we allowed nearly 2 hours before experiments at $43.3^{\circ} \mathrm{C}$ for the initial plasma expansion that occurs during rest $(12)$ and work $(13,14)$ in a hot environment. Active prevention of net dehydrative water loss also should have minimized variation in blood volume during the studies.

Conceivably the risk of cumulative thermal effects of each work load upon the one that followed would make circulatory responses to a given level of oxygen consumption dependent upon the influence of previous tests. Correction of this defect would have necessitated either more frequent catheterizations of each subject or, worse yet, comparison of different men at different levels of oxygen consumption. Williams and colleagues (2), who repeatedly studied two heatacclimatized men on separate days at various mild to severe work loads, found no significant temperature-induced change in cardiac output using the acetylene method. Thus the decrements we observed at higher work loads could be related to the cumulative heat stress in unacclimatized subjects.

The use of only moderate to severe exercise in these conditions limits interpretation of responses to conditions in which the metabolic heat load approaches or exceeds the environmental heat load. Although cardiac output was not increased by high ambient temperature when exercise required greater than $40 \%$ of maximal oxygen consumption, demands for heat dissipation ultimately may become a primary stimulus for regulating cardiac output when exercise is mild and prolonged (15, 16). However, longitudinal comparisons at normal and high ambient temperatures have not been made in a sufficient number of unacclimatized men.

The short duration of exercise precluded any possible attainment of either a circulatory or thermal steady state. However, it is unlikely that either could be attained under such severe conditions $(3,16)$. Since the rate of increase in cardiac output was essentially the same at both temperatures, the effect of high ambient temperature on cardiac output was not affected by the duration of exercise. In addition, the data of Asmussen (1) suggest that, had exercise been prolonged, cardiac output would not have continued to increase at $43.3^{\circ} \mathrm{C}$ above temporally equivalent values at lower temperatures. Indeed, prolongation of work ( $8.6 \%$ grade, 3.5 miles per hour) in a warm, humid environment $\left(30.6^{\circ} \mathrm{C}\right.$ $\left.\mathrm{db}, 27.6^{\circ} \mathrm{wb}\right)$ resulted in a fall in cardiac output below control values at $22^{\circ} \mathrm{C}(1)$.

Cardiac output methodology. Rapid central venous injection and rapid sampling of aortic blood eliminated distortions of the indicator dilution curves and also the large variability imposed by peripheral injections and sampling, by vasoconstriction of peripheral vasculature during exercise (17), and by nonuniform distribution of dye in peripheral arteries (6). The variance of cardiac output (coefficient of variation, $4.7 \%$ ) was very much less than that usually found during exercise $(6,18,19)$. Indeed serial measurements revealed a hitherto unobserved time trend for progressive increments in total blood flow that precluded precise definition of a "steady state."

The major methodological limitation was the nonspecific changes in calibration of dye concentration in blood that occurred between rest and exercise in all but one subject (MW). Increased light scattering by a greater number of red blood cells per unit volume may have resulted from in- 
creased hematocrit. Decreased red cell volume accompanying general intracellular dehydration was not found when the possibility was examined in one man. Observed changes in hematocrit were quite small, but changes with assumption of erect posture were not examined. Nevertheless, no further significant change in calibration occurred after the initial period of exercise. Since calibration was made only at the end of each work load, reversion of calibration values toward those obtained during rest could have occurred during recovery, but this would have obscured increments in cardiac output with time. The responses of MW, who showed no significant change in calibration, were identical to those of the rest of the group, indicating that calibration probably remained constant once exercise had commenced. Furthermore, we have observed no changes in calibration made from blood taken at different times (15 to 20 minutes and 50 to 60 minutes) during or shortly after prolonged mild exercise at $48.4^{\circ} \mathrm{C}(16)$.

Central blood volume methodology. In addition to elimination of problems cited above, central sampling prevented the large errors in determination of CBV due to gross disparities between aortic and peripheral transit times induced by peripheral vasoconstriction during exercise (7, 8). Indeed, Schlant and associates (20) observed a close correlation between a direct measurement of $\mathrm{CBV}$ and this volume as determined by the Stewart-Hamilton method with central injection and sampling. However, measurements of CBV could have been distorted by sampling from the aorta at the origin of the left subclavian artery rather than from the root. Theoretically, transit time to the former sampling site could be reduced by decreased blood flow to the carotid arteries and to arm muscle during severe leg exercise (21), causing a spurious decrease in CBV at either temperature. Reduced carotid arterial flow probably does not attend exercise (21), whereas decrements in flow to arm muscle would be more than counterbalanced by the large increase in cutaneous blood flow to the arms in the heat (22). This would oppose the decrements in $\mathrm{CBV}$ at $43.3^{\circ} \mathrm{C}$ by increasing MTT. The close proximity in distance and time of our sampling site to the root of the aorta and the small fraction of cardiac output delivered to the arms and shoulders during heavy leg exercise undoubtedly minimized any spurious changes in CBV resulting from redistribution of blood flow. Results from AJ, in whom the catheter rested in the root of the aorta, were identical to those obtained from the other subjects, indicating that the slightly more distal sampling exerted negligible influence on either the direction or magnitude of changes in $\mathrm{CBV}$ with temperature.

Implications of this study. As indicated above, our results should not be construed to apply to all intensities of work in the heat, since mechanisms of cardiovascular regulation may depend upon both the severity and duration of work. If, as limited evidence suggested $(15,16)$, cardiac output is augmented by heat stress when circulatory requirements for oxygen transport are small, levels of work must have been attained at which metabolic demands upon the circulation either exceeded or took precedence over thermal requirements for heat transfer. Because our subjects were not in thermal balance and ambient water vapor pressure $(22 \mathrm{~mm} \mathrm{Hg}, 33 \%$ relative humidity) was sufficient at $43.3^{\circ} \mathrm{C}$ to prevent evaporation of all sweat, their total heat stress could not be determined. Nevertheless, metabolic heat loads clearly exceeded that of the environment at higher work loads. Does the circulation respond differently to exogenous and endogenous heat loads? Effects of the latter were studied by Grimby and Nilsson (23), who found that, during experimentally induced fever (by pyrogen injection), increments in cardiac output due to fever became progressively less as oxygen uptake was increased by exercise until experimental and control values converged at about $2 \mathrm{~L}$ per minute.

In our study cardiac output was affected minimally by environmentally induced elevation of core temperature during work that required from 1.88 to $2.19 \mathrm{~L}$ of oxygen per minute ( 49 to $58 \%$ of maximal oxygen intake). Despite $15 \%$ reductions in $\mathrm{CBV}$ and stroke volume, compensation was achieved by faster heart rate and more rapid circulation time. Acute adaptation was therefore dependent upon the magnitude and time sequence of alterations in the distribution of cardiac output, not in its magnitude. In contrast to responses at $25.6^{\circ} \mathrm{C}$ where hepatic-splanchnic blood flow falls 
with exercise at about $25 \%$ of maximal oxygen intake, this fall was initiated by even the mildest exercise at $43.3^{\circ} \mathrm{C}(3)$. Renal blood flow diminished also $(6,24)$. Whereas a greater fraction of the cardiac output undoubtedly is distributed to skin, the addition of highly unsaturated venous blood from splanchnic and other regions to arterialized blood from cutaneous veins undoubtedly accounted for the similarity of mixed a-v oxygen differences in the two environments at 49 to $58 \%$ of maximal oxygen consumption.

In addition to augmented redistribution of blood flow at $43.3^{\circ} \mathrm{C}$, the reductions in $\mathrm{CBV}$ and stroke volume reflected a peripheral displacement of blood volume rather than an effect of dehydration, which was prevented. It is not known whether this displacement of blood occurred during supine rest or with assumption of upright posture. There is evidence of significant reduction in pulmonary blood volume during rest in a hot environment (25-27). Normally CBV is reduced about 20 to $30 \%$ with the change from supine to upright posture, whereas it rapidly returns to the supine control value with exercise (28). This increase in CBV with exercise may be achieved by the peripheral venoconstriction that normally accompanies exercise (29). Bevegård and Shepherd consider this to be an important mechanism for redistribution of circulating blood from the capacitive venous system to the arterial circulation with exercise, while concomitantly serving to maintain adequate ventricular filling volume (29). Since this response is abolished by heat $(29,30)$, an absence of peripheral venoconstriction may have prevented central redistribution of pooled peripheral blood in our subjects. This, coupled with a normal increase in cardiac output, may have depleted "preventricular sumps" thus diminishing $\mathrm{CBV}$ and stroke volume with a concomitant rise in heart rate. Alternatively, the normal sequence of changes from rest to exercise could have been superimposed upon an initially lower CBV in the heat.

The reduction in CBV was always reflected in a marked decrease in MTT at $43.3^{\circ} \mathrm{C}$. In addition, during a given level of exercise, cardiac output increased with time, whereas MTT decreased and CBV remained essentially constant. Accordingly, as cardiac output increased with time or work load, circulation time decreased almost proportionally. Apparently the cutaneous circulation simulated a large a-v shunt, providing a more rapid circulatory transit than splanchnic organs and kidneys whose flows are markedly reduced under these conditions.

Unlike responses to the two lower work loads at $43.3^{\circ} \mathrm{C}$, adequate compensation was probably not achieved during the higher work loads, which required 2.4 to $2.85 \mathrm{~L}$ of oxygen per minute (63 to $73 \%$ of maximal oxygen intake). At these higher work loads our unacclimatized subjects no longer could compensate for reduced CBV and stroke volume in the heat. As a result of early attainment of maximal heart rate at lower work loads at $43.3^{\circ} \mathrm{C}$, cardiac output could no longer be increased to meet the demands of higher work loads. Nevertheless, demands for oxygen transport were met adequately by increased extraction of oxygen. In addition to maximal reduction in visceral blood flow (3), flows to both skin and working muscle probably must have been compromised also. Certainly the wider total a-v oxygen differences at $43.3^{\circ} \mathrm{C}$ could not have resulted solely from addition of very unsaturated splanchnic and renal venous blood, which was a much smaller fraction of total venous return at these work loads. Indeed, there is some evidence that cutaneous blood flow is drastically reduced as exhaustion is approached during exercise $(2,3$, $31)$. Decrements in hepatic and renal blood flow probably did not adequately compensate for failure to increase cardiac output. Demonstration of increased blood lactate concentration under similar conditions suggests that blood flow to working skeletal muscle was compromised also (2). However, Rowell and co-workers (3) observed only small increments (statistically nonsignificant) in blood lactate concentration in unacclimatized subjects under conditions identical to those of the present study. Thus summation of two major competitive stresses upon the circulation heralds the impairment of work capacity of the body and functional capacity of the cardiovascular system. The hallmark of these phenomena is the final widening of the a-v oxygen difference, as visceral and probably cutaneous blood flow is reduced by marked vasoconstriction, despite elevated core temperature. Since visceral metabolism, at least hepatic, appears to be maintained (32), over- 
heating of the tissues is likely to ensue. The severity of these thermal effects is not likely to be appreciated from measurements of rectal temperature (3). The uniform occurrence of severe nausea and abdominal pain, before exhaustion at $43.3^{\circ}$ $\mathrm{C}$, seems to represent the symptomatic awareness of visceral ischemia or hyperthermia.

Inasmuch as exhaustion, under these conditions, may be relieved dramatically by rapidly lowering the ambient temperature even though exertion continues (33), neither dehydration nor depletion of metabolic substrates can account for the obvious reduction in work capacity. It is important to emphasize that total oxygen intake, which is often referred to as work capacity, is the product of rate of oxygen intake per unit time and duration of time. Although in acute experiments maximal oxygen intake was not reduced even in the heat, the duration of time in which this may be continued is markedly shortened.

Failure to maintain the needed level of cardiac output when strenuous exercise is performed in the heat indicates impairment of cardiovascular function. This is not limited by heart rate, and indeed the possibility of fatigue from prolongation of excessive tachycardia is not documented. In fact, Saltin and Stenberg reported that one individual was able to maintain a maximal heart rate of 190 beats per minute during 90 minutes of exercise (34). Circulatory impairment under the conditions of combined metabolic and thermal stresses may be primarily due to impaired diastolic filling of the ventricles and consequently impaired systolic ejection, despite a vigorous myocardial contraction. An important contributory factor is a substantial reduction in central blood volume due to peripheral displacement. Peripheral venous pooling in the upright posture may augment this. The fact emphasized by Dill (33) that rapid lowering of ambient temperature allows normal men to continue exertion after exhaustion is reached in the heat suggests the predominant importance of peripheral displacement of vascular volume in the etiology of impaired work capacity and cardiovascular function. Thus with appropriate combinations of circulatory stresses, even normal subjects may develop a form of "circulatory failure." The situation is analogous to that of the limited cardiac patient who is unable to increase cardiac output with exercise and must alternatively rely upon blood flow redistributed from internal organs to increase blood supply to working muscle (21).

\section{Summary}

Cardiac output, central blood volume (CBV), oxygen consumption, and heart rate were determined in six normal young men unacclimatized to heat in response to exercise at $25.6^{\circ} \mathrm{C}\left(78^{\circ} \mathrm{F}\right)$ and $43.3^{\circ} \mathrm{C}\left(110^{\circ} \mathrm{F}\right)$. Indocyanine green was injected into the right atrium and sampled from the aortic arch. Seven measurements of cardiac output were made in each man during each of four intensities of exercise at $25.6^{\circ} \mathrm{C}$ and repeated 3 to 4 weeks later in the same men at $43.3^{\circ} \mathrm{C}$. Exercise required from 43 to $86 \%$ of the maximal oxygen intake at both temperatures.

Oxygen consumption during exercise was unaffected by ambient temperature; heart rates were markedly elevated at $43.3^{\circ} \mathrm{C}$. During each 15 minute period of exercise cardiac output showed a small but highly significant increase with time. Heart rate also increased with time, but oxygen intake stayed constant.

Cardiac output was very significantly ( $p<$ 0.0005 ) decreased by high ambient temperature. At the two lower work loads the decrease was very small ( 170 to $370 \mathrm{ml}$ per minute). With increasing severity of exercise the reduction in cardiac output became more pronounced ( 1,130 to 1,240 $\mathrm{ml}$ per minute). Three subjects attained nearly maximal heart rates during the third work load and failed to increase cardiac output for the final work load, which was performed with normal increment in oxygen intake but widened arteriovenous oxygen difference.

At the two lower levels of exercise at $43.3^{\circ} \mathrm{C}$, CBV was reduced $16 \%$ below control values at $25.6^{\circ} \mathrm{C}$. Decrements in CBV were closely paralleled by percentage decreases in stroke volume (also 16\%). Reduction in CBV was related to decrements in mean transit time rather than to changes in cardiac output. At the two higher work loads $\mathrm{CBV}$ and stroke volume were still reduced, but reduction in the latter became more pronounced.

Added demands for heat dissipation during moderate to severe exercise of short duration (15 minutes) at high ambient temperature are met by repartitioning cardiac output rather than by increasing it. The fall in CBV and stroke volume 
indicates a redistribution of blood from the "core" to the periphery at $43.3^{\circ} \mathrm{C}$ coincident with a more rapid circulation time. The failure to provide adequate increments in cardiac output constitutes an important contributory factor limiting man's capacity for work in the heat.

\section{Acknowledgments}

The authors acknowledge with sincere gratitude the tireless effort of Evelyn C. Steen, R.N., and the courageous participation of our subjects. We are grateful to Dr. Richard Kronmal and Mr. Richard Gilbert for their very able and generous efforts with statistical analysis. Also, the advice and assistance with statistical analysis by Dr. Edward Perrin, Dr. Ruth Kirk, and Miss Verona Hofer are appreciated.

\section{References}

1. Asmussen, E. The cardiac output in rest and work in humid heat. Amer. J. Physiol. 1940, 131, 54.

2. Williams, C. G., G. A. G. Bredell, C. H. Wyndham, N. B. Strydom, J. F. Morrison, J. Peter, P. W. Fleming, and J. S. Ward. Circulatory and metabolic reactions to work in heat. J. appl. Physiol. 1962, 17, 625.

3. Rowell, L. B., J. R. Blackmon, R. H. Martin, J. A. Mazzarella, and R. A. Bruce. Hepatic clearance of indocyanine green in man under thermal and exercise stresses. J. appl. Physiol. 1965, 20, 384.

4. Radigan, L. R., and S. Robinson. Effects of environmental heat stress and exercise on renal blood flow and filtration rate. J. appl. Physiol. 1949, 2, 185.

5. Grande, F., and H. L. Taylor. Adaptive changes in the heart, vessels, and patterns of control under chronically high loads in Handbook of Physiology, section 2, vol. 3, Circulation. Washington, D. C., American Physiological Society, 1964, p. 2615.

6. Sleeper, J. C., H. K. Thompson, Jr., H. D. McIntosh, and R. C. Elston. Reproducibility of results obtained with indicator-dilution technique for estimating cardiac output in man. Circulat. Res. 1962, $11,712$.

7. McIntosh, H. D., W. L. Gleason, D. E. Miller, and J. M. Bacos. A major pitfall in the interpretation of "central blood volume." Circulat. Res. 1961, 9, 1223.

8. Marshall, R. J., and J. T. Shepherd. Interpretation of changes in "central" blood volume and slope volume during exercise in man. J. clin. Invest. 1961, 40, 375.

9. Taylor, H. L., E. Buskirk, and A. Henschel. Maximal oxygen intake as an objective measure of cardio-respiratory performance. J. appl. Physiol. 1955, 8, 73.

10. Fox, I. J., W. F. Sutterer, and E. H. Wood. Dynamic response characteristics of systems for continuous recording of concentration changes in a flowing liquid (for example, indicator-dilution curves). J. appl. Physiol. 1957, 11, 390.

11. Piwonka, R. W., S. Robinson, V. L. Gay, and R. S. Manalis. Preacclimatization of men to heat by training. J. appl. Physiol. 1965, 20, 379.

12. Glickman, N., F. K. Hick, R. W. Keeton, and M. M. Montgomery. Blood volume changes in men exposed to hot environmental conditions for a few hours. Amer. J. Physiol. 1941, 134, 165.

13. Robinson, S. Physiological adjustments to heat in Physiology of Heat Regulation and the Science of Clothing, L. H. Newburgh, Ed. Philadelphia, W. B. Saunders, 1949, p. 193.

14. Kozlowski, S., and B. Saltin. Effect of sweat loss on body fluids. J. appl. Physiol. 1964, 19, 1119.

15. Kraning, K. K. II, H. S. Belding, and B. A. Hertig. Use of sweating rate to predict other physiological responses to heat. J. appl. Physiol. 1966, 21, 111.

16. Rowell, L. B., K. K. Kraning II, J. W. Kennedy, and T. O. Evans. Central circulatory responses to work in dry heat before and after acclimatization. In preparation.

17. Wang, Y., L. Rowell, G. Blomqvist, and H. L. Taylor. Observations on redistribution of systemic blood flow during upright exercise in man. Fed. Proc. 1964, 23, 111.

18. Hanson, J. S., and B. S. Tabakin. Simultaneous and rapidly repeated cardiac output determinations by dye-dilution method. J. appl. Physiol. 1964, 19, 275.

19. Levy, A. M., B. S. Tabakin, and J. S. Hanson. Cardiac output in normal men during steady-state exercise utilizing dye-dilution technique. Brit. Heart J. 1961, 23, 425.

20. Schlant, R. C., P. Novack, W. L. Kraus, C. B. Moore, R. W. Haynes, and L. Dexter. Determination of central blood volume. Comparison of StewartHamilton method with direct measurements in dogs. Amer. J. Physiol. 1959, 196, 499.

21. Wade, O. L., and J. M. Bishop. Cardiac Output and Regional Blood Flow. Oxford, Blackwell, 1962, p. 103.

22. Shepherd, J. T. Physiology of the Circulation in Human Limbs in Health and Disease. Philadelphia, W. B. Saunders, 1963, p. 163.

23. Grimby, G., and N. J. Nilsson. Cardiac output during exercise in pyrogen-induced fever. Scand. J. clin. Lab. Invest. 1963, 15 (suppl. 69), 44.

24. Grimby, G. Renal clearances during prolonged supine exercise at different loads. J. appl. Physiol. 1965, 20, 1294.

25. Glaser, E. M., F. R. Berridge, and K. M. Prior. Effects of heat and cold on the distribution of blood within the human body. Radiological investigations of the liver, lungs, and heart. Clin. Sci. 1950, 9, 181.

26. Glaser, E. M. The effects of cooling and warming on the vital capacity, forearm and hand volume, and skin temperature of man. J. Physiol. (Lond.) 1949, 109, 421. 
27. Frayser, R., J. C. Ross, H. S. Levin, J. V. Messer, and J. Pines. Effect of increased environmental temperature on pulmonary diffusing capacity. $\mathrm{J}$. appl. Physiol. 1966, 21, 147.

28. Wang, Y., G. Blomqvist, L. B. Rowell, and H. L. Taylor. Central blood volume during upright exercise in normal subjects. Fed. Proc. 1962, 21, 124.

29. Bevegård, B. S., and J. T. Shepherd. Changes in tone of limb veins during supine exercise. J. appl. Physiol. 1965, 20, 1.

30. Wood, J. E., and D. E. Bass. Responses of the veins and arterioles of the forearm to walking during acclimatization to heat in man. J. clin. Invest. $1960,39,825$.
31. Barger, A. C., W. F. Greenwood, J. R. DiPalma, J. Stokes III, and L. H. Smith. Venous pressure and cutaneous reactive hyperemia in exhausting exercise and certain other circulatory stresses. J. appl. Physiol. 1948, 2, 81.

32. Rowell, L. B., T. O. Evans, J. W. Kennedy, and J. R. Blackmon. Splanchnic lactate and pyruvate uptake during prolonged heavy exercise in man. Fed. Proc. 1966, 25, 334.

33. Dill, D. B. Regulation of the heart rate in Work and the Heart, F. F. Rosenbaum and E. L. Belknap, Eds. New York, Hoeber, 1959, p. 65.

34. Saltin, B., and J. Stenberg. Circulatory response to prolonged severe exercise. J. appl. Physiol. $1964,19,833$. 